\title{
Rapid Heating Concepts in Sintering
}

\author{
Randall M. German* \\ College of Engineering, San Diego State University, San Diego, California, 92182 USA
}

(Received March 28, 2013; Accepted April 16, 2013)

\begin{abstract}
Powder metallurgy applied rapid heating to sintering starting year 1900. Since 1970 the study has intensified. Now rapid sintering concepts embrace a spectrum of options ranging from dunk cycles to microwave, induction, exothermic, electric field, and spark approaches. Most of the efforts are targeting reduced microstructure coarsening during sintering, although reduced material decomposition is another common goal. The efforts are impressive for simple shapes and success metrics such a small grain size after densification. Several barriers need to be removed prior to application in powder metallurgy commercial sintering. Rapid heating research needs to focus on significant property gains, accurate product dimensions, and lower costs. So far each property gain obtained with rapid heating is matched by traditional sintering and composition changes. Several examples are cited to show the goals for the next round of innovations.
\end{abstract}

Keywords: Sintering, Rapid heating, Electric field, Microwave, Hot pressing, Novel technology

\section{Introduction}

The first application of rapid heating in powder metallurgy arose in sintering lamp filaments, relying on the electric furnace concept invented by Moissan (1906 Nobel Prize in chemistry) [1-4]. The concept was initially termed "resistance sintering under pressure" then "spark sintering" [5-6]. Early cycles reached density in seconds, so fast sintering is not new. In the last few decades, commercial research rapid sintering machines arose in several laboratories. Adoption of the concept by the elctrodischarge machining industry came with the suggestion of "spark plasma sintering." However, subsequent research shows there is no plasma [7], so spark sintering is representative of the several variants [8].

Vergnon et al. [9] called sintering cycles lasting just a few seconds "flash sintering". There is no formal definition of rapid heating or flash sintering, but generally a heating rate over $10^{\circ} \mathrm{C} / \mathrm{s}$ is implied and some reports reach $600^{\circ} \mathrm{C} / \mathrm{s}$. Traditional industrial sintering relies on heating rates of $10^{\circ} \mathrm{C} / \mathrm{min}\left(0.167^{\circ} \mathrm{C} / \mathrm{s}\right)$, or about 60 -fold slower. However, to date such cycles are not realistic for powder metallurgy production. Limitations arise in energy availability, process controls, and defects arising from rapid heating. A balance between these various attributes tends to show realistic gains with heating rates in the 10 to $20^{\circ} \mathrm{C} / \mathrm{s}$ range, by any of the available approaches.

Several factors combine to make rapid heating interesting for sintering [10]. These include shifts in diffusion events as temperature increases to changes in production economics. Searcy et al. [11-12] contend thermal gradients arise in rapid heating that are significant; there is little benefit if rapid heating occurs without thermal gradients. Fast heating sustains the thermal gradient and this appears to be a key requirement to accelerate sintering. Thus, some generalized points with respect to rapid heating in sintering are as follows:

- surface energy - a powder has energy stored in the form of surface energy, at lower temperatures surface diffusion is a dominant sintering mechanism because of the high initial surface area; surface dissipates surface energy via neck growth without densification while rapid heating preserves surface energy to temperatures where densification processes are active to improve sintered density,

- instability - materials that decompose during heating,

*Corresponding Author : Randall M. German, TEL: +1-619-594-6076, FAX: +1-619-594-6061, E-mail: randgerman@gmail.com 
especially diamond and some oxides used in electronics (lead-containing titanates), respond to rapid heating with minimized decomposition during sintering,

- microstructure coarsening - slow heating cycles allow more time for grain coarsening, while fast cycles reduce grain coarsening by separating densification from grain growth, an approach of great benefit in nanoscale materials,

- economics - quick cycles, as associated with rapid heating, require less furnace time, meaning that more product is sintered without requiring the purchase of more equipment.

Much speculation exists on the possible gains from rapid heating. Unfortunately, relatively few measurements directly monitor the effects, so most of the conjecture is based on assumptions and calculations. The notions include the possibility of surface-core temperature gradients that induce dislocation slip or climb, reduced grain growth with more grain boundary diffusion induced densification, thermal gradient induced diffusion.

Thermal stresses induce dislocation motion during rapid heating, giving plastic flow and dislocation climb [13]. The grain size reduction with rapid heating reflects separation of grain growth and densification. Fast heating is beneficial when the densification process has a higher activation energy versus the activation energy for grain coarsening. As a consequence, rapid heating reduces the time during which grain growth occurs, resulting in a smaller grain size at each density level. A good example is in a study of grain size versus sintered density using alumina doped with $200 \mathrm{ppm}$ magnesia [14]. The sintered grain size after rapid heating to $1850^{\circ} \mathrm{C}(2123 \mathrm{~K})$ was almost half that after conventional sintering to the same density. The rapid heating cycle generates a smaller grain size at each density. Since heat is provided at the exterior of the powder compact, substantial thermal gradients arise during rapid heating. These thermal gradients are sufficient to improve densification and diffusion during sintering [15-16].

The investment community says, "... with all technology the good news comes first." For rapid sintering the gain is a smaller grain size for a given density. The bad news on rapid heating cycles is substantial. One signifi- cant problem is the damage induced by large thermal stresses, leading to cracking, warpage, and rupture from trapped gases. In a study on rapid heating cutting tools, the maximum component thickness attainable without cracking was $10 \mathrm{~mm}$. Additionally, rapid heating exhibits less advantage as the component mass increases. Heat transfer is limited in thick sections, so small components respond best.

Another difficulty with rapid heating is the "line of sight" requirement for radiation delivery. This restricts rapid heating to simple geometries and usually to sintering one component at a time. For example, microwave sintering claims interior heating, but a susceptor powder such as silicon carbide is usually packed around the component, which then only allows exterior heating. Otherwise thermal runaway occurs as the material heats and couples with the microwave, making process control difficult. With rapid heating no lubricant or binder is allowed, otherwise the compact ruptures from rapid polymer decomposition and evaporation. Thus, a separate slow thermal cycle is used to remove volatile species prior to rapid sintering. In a microwave sintering facility for cemented carbides, sintering occurred in $8 \mathrm{~min}$ at $1400^{\circ} \mathrm{C}(1673 \mathrm{~K})$, but dewaxing prior to microwave sintering took $8 \mathrm{~h}$ in a separate furnace.

Because of the "one at a time" character of rapid heating technologies, productivity is low. With respect to the cost of sintering, production experience shows a microwave furnace produces about $1 \mathrm{~kg}$ of sintered product per hour at a capital cost twice that of a traditional batch furnace producing $4 \mathrm{~kg} / \mathrm{h}$. Still the conceptual learning from rapid heating is important in pulling various aspects of sintering into a coherent conceptualization.

\section{Early Demonstrations}

One means to execute rapid heating is to employ a dunk cycle. At tube or pusher furnace is preheated to the peak temperature and the powder compact is inserted into the hot furnace [17]. The translation rate into the furnace determines the heating rate, reaching $10^{\circ} \mathrm{C} / \mathrm{s}$. Fig. 1 plots sintered density for $\mathrm{SnO}_{2}$ doped with three levels of iron (as an oxide) [18]. Small samples of inserted into a $1200^{\circ} \mathrm{C}(1473 \mathrm{~K})$ furnace produce significant densification in the first minute. 


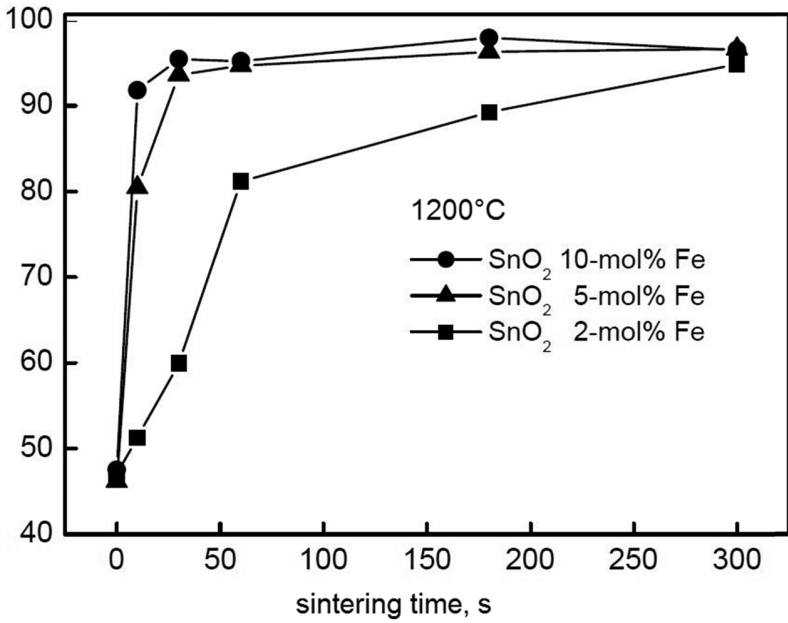

Fig. 1. Sintered density for tin oxide $\left(\mathrm{SnO}_{2}\right)$ doped with various levels of iron (in the form of oxide) showing the remarkably rapid densification possible with dunk heating cycles [18]. The furnace was set to $1200^{\circ} \mathrm{C}(1473 \mathrm{~K})$ for these trials.

Besides fast firing with dunk cycles, intense energy input routes have been used, such as electric discharges, exothermic reactions, or heating using microwave, induction, plasma, infrared, or laser sources. In newer approaches, the temperature rise reaches upwards to $200^{\circ} \mathrm{C} / \mathrm{s}$. A common variant is to directly discharge electric current through the powder compact, a process first termed spark sintering, but known by several names such as field effect sintering technology, spark plasma sintering, and electric current activated sintering; spark sintering is most descriptive since there is no plasma [19]. Many approaches add supplemental pressure to accelerate densification. The thermal mass of the die and punches slows heating and cooling, reducing productivity to levels similar to hot pressing. In direct comparisons the results from hot pressing and spark sintering are very similar in terms of grain size and density.

Rapid heating results in shrinkage rates near $1 \%$ per second. The manipulation of successful cycles comes from understanding the sintering mechanism and playing temperature change to advantage [20]. For example, surface diffusion, with a lower activation energy, tends to dominate lower temperature, early-stage sintering, while grain boundary diffusion tends to dominate higher temperature, late-stage sintering. With a nanoscale powder there is much initial surface area and little grain boundary area. As neck growth progresses the opposite is true, with more grain boundary area and less surface area. Grain growth accelerates as grain boundary area increases. More grain boundary diffusion occurs by jumping to a high temperature.

Calculations of rates for grain boundary diffusion, surface diffusion, and grain growth give estimates of the crossover points during different sintering cycles. Initially, at lower temperatures and higher surface areas, surface diffusion dominates. At higher temperatures, after grain boundaries form at the particle contacts, a crossover arises where grain boundary diffusion dominates, giving densification. Of course this is soon followed by grain growth. Rapid heating induces earlier dominance of densification, and if properly managed the short densification cycle minimizes grain growth. Such behavior is illustrated by solving for the surface diffusion and grain boundary diffusion fluxes during sintering for silver at various heating rates $-1,10$, and $100^{\circ} \mathrm{C} / \mathrm{s}$ [21]. The calculations are for $0.5 \mu \mathrm{m}$ powder at $523^{\circ} \mathrm{C}(800 \mathrm{~K})$. The intersections where surface and grain boundary diffusion are equal produce a locus of transition points. The higher the heating rate, the earlier grain boundary diffusion becomes dominant; fast heating leads to more grain boundary diffusion with concomitant sintering densification. This is one of the few cases where heating rate is analytically demonstrated with respect to a sintering benefit.

Exploration of fast heating rates most commonly examine electric discharges, dating back to the early 1900s. Traditional furnaces were limited in temperature capabilities, so direct electric passage through the compact avoided fabrication of a high temperature furnace. In the early work there was little focus on heating rate effects; indeed temperature measurement was immature so rates were not reported. Later concepts expanded the rapid heating to plasma and microwave approaches [22-25].

Several demonstrations show faster densification with faster heating. One example is given in Fig. 2 for titanium consolidated by spark sintering at $50 \mathrm{MPa}$ [26]. Three heating rates were used. Because of the thermal mass from the die, heating rates are limited to about $200^{\circ} \mathrm{C} / \mathrm{min}$ or $3.3^{\circ} \mathrm{C} / \mathrm{s}$. The fastest heating shows some densification advantage. Later efforts with faster rates did show considerable change in sintering. But rapid heating is restricted to small compacts. Performance gains come from small powders with a high surface area; naturally 


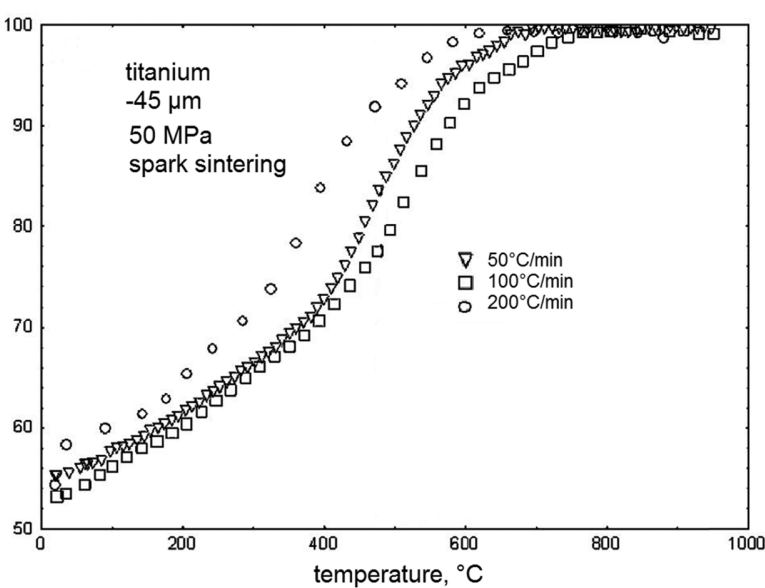

Fig. 2. Sintered density for spark sintering of titanium with $50 \mathrm{MPa}$ applied pressure at three heating rates [26]. The faster heating rate shows some densification advantage. Rapid heating benefits are most apparent at heating rates near $20^{\circ} \mathrm{C} / \mathrm{s}$.

this favors nanoscale powders. Densification and microstructure control are benefits, especially in materials otherwise difficult to sinter.

\section{Nanoscale Options}

Rapid heating experiments during the 1970s demonstrated sintering in seconds for nanoscale powders. For example, $22 \mathrm{~nm}$ yttria doped zirconia powder reached $99 \%$ density in $60 \mathrm{~s}$ after immersion into a furnace at $1300^{\circ} \mathrm{C}$ (1573 K), giving a final grain size of $100 \mathrm{~nm}$ [28]. Thus properties dependent on grain size improve [29-30]. The effect is pronounced with smaller particle sizes, as demonstrated using titania $\left(\mathrm{TiO}_{2}\right)$ sintered at $700^{\circ} \mathrm{C}(973 \mathrm{~K})$ for 8,12 , and $17 \mathrm{~nm}$ powders. For such trials, $0.2 \mathrm{~g}$ samples were subjected to heating rates estimated at $100^{\circ} \mathrm{C} / \mathrm{s}$. Extensive densification occurs in $20 \mathrm{~s}$ for the smaller powder and decreased with larger particle sizes. Subsequent results extend these ideas to other materials.

Nanoscale particles are sensitive to the combination of rapid heating and peak temperature, often exhibiting desintering with heating that is too fast or too hot. Higher temperatures decrease density due to retained impurities that evaporate after pore closure [31]. A good example is in sintering of yttria stabilized zirconia heated at $8^{\circ} \mathrm{C} / \mathrm{s}$. Peak temperature was held for $1 \mathrm{~min}$ and the sintered density increased to $1300^{\circ} \mathrm{C}(1573 \mathrm{~K})$, but above this temperature density decreased. The vapor pressure of trapped impurities increased with temperature, generating a pore pressure that increases with temperature to offset densification. Trials showed better densification with slower heating $\left(99.3 \%\right.$ for $10^{\circ} \mathrm{C} / \mathrm{min}$ versus $90.7 \%$ for $500^{\circ} \mathrm{C} / \mathrm{min}$ or $8.3^{\circ} \mathrm{C} / \mathrm{s}$ ), with less difficulty if prolonged calcination treatments were first used to remove the impurities [32]. For comparison, conventional sintering results in a lower density and larger grain size, but evaporates impurities prior to pore closure. Small grain sizes and fast densification are evident gains with nanoscale powders, but contamination mandates slower heating.

The combination of rapid heating and nanoscale particles gives mixed benefits and problems:

- high sintering stress to enhance densification

- less time at low temperatures where the high surface area promotes surface diffusion without densification

- more surface energy preserved to higher temperatures where grain boundary diffusion, dislocation climb, plastic flow, and other densification processes are active

- more contamination and less time to volatilize contaminants

- smaller grain size at density

- component warping or even cracking

- rapid heating is restricted to small, low mass compacts.

\section{Rapid Heating Techniques}

Rapid sintering is an area of much invention. The demonstrations are exciting, but the production of consistent product is difficult. Thus, other than for metastable materials (sintered diamond, thermoelectric compounds, polymer-metal composites), where the time at temperature is short to minimize decomposition, traditional sintering avoids rapid heating. Even so, inventions abound and range from self-heating exothermic processes to closely coupled heating from induction, laser, microwave, electric discharge, or plasma energy sources.

\subsection{Exothermic}

An exothermic reaction is a means to rapidly heat the compact while simultaneously forming a compound. The thermite reaction between aluminum and iron oxide pow- 
ders generates molten iron (and alumina slag) for portable welding. Once ignited, the exothermic reaction is rapid. Such a reaction is a means to rapidly heat another powder compact. Alternatively, the constituent powders are reacted to form a compound that sinters using the reaction heat. Two or more powders are mixed and compacted. Once initiated, the reaction heat induces adiabatic temperature rise [33-36]. Thousands of systems are known, including aluminides $\left(\mathrm{Ni}_{3} \mathrm{Al}\right)$, silicides $\left(\mathrm{MoSi}_{2}\right)$, carbides (TiC), nitrides ( $\mathrm{ZrN})$, and borides $(\mathrm{MgB})$. Coble termed the process reactive sintering, as is evident when the reaction provides sufficient heat to sinter the newly formed product [37]. Often a liquid phase forms during the reaction to accelerate sintering densification. The reaction propagates by passing heat through the surrounding material, similar to how a fire advances, but the large thermal and shrinkage gradients distort the component. Thus, only in a few applications, such as sintering $\mathrm{MoSi}_{2}$ heating elements, has the process been commercialized.

For reactive sintering, the ingredients are mixed in the desired ratio. For example to sinter nickel aluminide $\mathrm{NiAl}$, nickel and aluminum powders are mixed and compacted in an equal atomic ratio. The reaction initiates near $600^{\circ} \mathrm{C}(873 \mathrm{~K})$ and is self-heating to $1200^{\circ} \mathrm{C}(1473)$ or higher with a 2 to $5 \mathrm{~mm} / \mathrm{s}$ propagation velocity. The velocity depends on density and particle size. For nonreactive systems, a sacrificial reactant is used to generate heat [38]; Mn mixed with $\mathrm{S}$ is one option. The formation of $\mathrm{MnS}$ heats an embedded compact. A variant is exothermic hot pressing where an external pressure is applied during the reaction. Process control is difficult.

\subsection{Electric Current}

Electrical discharge heating is an old idea used in sintering tungsten, tantalum, molybdenum, and other high melting temperature metals. It was revived by Inoue for sintering magnets in cycles lasting $100 \mathrm{~s}$ [39]. Heating rates of $10^{\circ} \mathrm{C} / \mathrm{s}$ arise with electric current passage though graphite tooling [40]. Such ideas spread and became a favorite means for rapid heating with simultaneous pressurization.

Process control is complicated by substantial shifts in conductivity during densification. At the start of the consolidation cycle even metallic powders are poor conduc- tors, but as densification progresses they bond to become conductive. In some cases the compact densifies to become so conductive that it fails to heat properly. On the other hand, nonconductor materials rely on heating the containment die. For oxide coated materials, such as aluminum, the situation is complex. Experiments with $125 \mu \mathrm{m}$ water atomized aluminum show difficult initial current flow through the compact oxides. Even so spark sintering delivers $99.7 \%$ density using a cycle of $0.3^{\circ} \mathrm{C} / \mathrm{s}$ to $600^{\circ} \mathrm{C}(873 \mathrm{~K})$ with a $30 \mathrm{~min} 40 \mathrm{MPa}$ pressure hold [41]. Hot pressing gives essentially the same result, and when the strength and elongation are compared, spark sintered gave $93 \mathrm{MPa}$ and $48 \%$ and hot pressing gave 90 $\mathrm{MPa}$ and 50\%. Spark sintering resulted in higher properties at short times, probably due to erosion of the surface films. Still both approaches plateaued at similar properties when fully densified.

The merits of spark sintering arise from rapid heating, short hold times, applied pressure, and electric field induced diffusion [42-45]. Most are attainable in several hot consolidation approaches; rapid hot pressing using exothermic reactions, microwave hot pressing, induction, or capacitive discharge. Likewise, quick hot isostatic pressing is performed using cycles of just one minute [46]. By heating rapidly, low temperature surface diffusion is avoided, carrying more of the surface energy to high temperatures where grain boundary diffusion is active [47]. Exothermic hot pressing and reactive hot isostatic pressing do not require electric current, are fast, and deliver small grain sizes in full dense materials [48-55].

For small compacts, spark sintering reaches the current densities where electromigration supplements diffusion, usually at current densities over $1,000 \mathrm{~A} / \mathrm{cm}^{2}$ [56]. The supplemental current effect scales with the atomic drift velocity $V$ due to the electric field $E$,

$$
V=\frac{D Z e E}{k T}
$$

where $D$ is the inherent temperature-dependent diffusivity, $Z$ is a material factor near $0.1, e$ is the electric charge $\left(1.610^{-19} \mathrm{C}\right), k$ is Boltzmann's constant, and $T$ is the absolute temperature.

To assess the supplemental effect, assume copper at $800^{\circ} \mathrm{C}(1073 \mathrm{~K})$. At this temperature the volume diffusivity is $2.510^{-15} \mathrm{~m}^{2} / \mathrm{s}$ and in $1 \mathrm{~s}$ the mean atomic displacement is $0.123 \mu \mathrm{m}$. With $5 \mathrm{~V}$ applied over a $3 \mathrm{~mm}$ 
compact, the electric field is $1.6710^{3} \mathrm{~V} / \mathrm{m}$, so the additional displacement due to electromigration is $4.510^{-6}$ $\mu \mathrm{m}$. This is a trivial contribution (about $0.004 \%$ ). However, at the onset of spark sintering the small necks concentrate current. This is analogous to the pressure concentration at low densities. The concentrated current makes a measurable contribution to particle bonding [57-58]. As the necks enlarge, the current density declines and electromigration is lost. However, the electron wind also works to accumulate vacancies, resulting in pores in the sinter necks. Diffusion fluxes during sintering are based on concentration gradients, but electromigration adds a term that includes charge, field, and mobility [59]. Electromigration requires $\mathrm{DC}$ pulses of $1 \mathrm{~s}$ or more, as confirmed by $15 \mathrm{~s}$ pulses in diamond sintering, but most research efforts rely on short 2 to $3 \mathrm{~ms}$ pulses that fail to induce electromigration benefits. Indeed in experiments by the author, a head to head comparison of spark sintering to hot pressing (same powder, green density, heating rate, pressure, temperature, and time); rapid hot pressing produced a higher density since there was no electromigration induced pores.

Speculation arises on new phenomena in spark sintering and the unanswered influences includes -

- grain boundary structure changes, such as improved ledge formation and migration

- altered grain boundary migration and segregation

- electromigration enhanced diffusion.

Smaller grain sizes result when large voltage gradients are used, even without the application of pressure. This is due to grain boundary films preferentially interacting with the electric field. For metastable materials, such as tungsten carbide, diamond, cubic boron nitride, boron suboxide, and thermoelectric telluride compounds, decomposition occurs during consolidation. The metastable materials exhibit decomposition behavior that varies with the time-temperature-pressure combination as follows [60]:

$$
\frac{d x}{d t}=\beta \exp \left[-\frac{E+P \Delta V}{R T}\right]
$$

where $x$ is the mass fraction decomposed, $t$ is the time, $T$ is the temperature, $E$ is the decomposition activation energy, $P$ is the pressure, $\Delta \mathrm{V}$ is the activation volume, and $R$ is the gas constant. The rate constant $\beta$ depends on the atmosphere. For example, the decomposition activation energy for diamond is from 728 to $1159 \mathrm{~kJ} / \mathrm{mol}$ depending on crystal orientation and the activation volume is $10 \mathrm{~cm}^{3} / \mathrm{mol}$. For unstable materials, such as diamond, this model shows the benefits of sintering at lower temperatures using shorter times as possible by spark sintering. However, as full density is approached, the current concentration decreases and the benefits versus hot pressing or other consolidation routes is lost. The key gain is fast heating, an advantage well known in sintering and pressure-enhanced sintering without the need for electric fields.

In flash sintering of $60 \mu \mathrm{m}$ iron powder size starting at $73 \%$ green density cycle of $800^{\circ} \mathrm{C}(1073 \mathrm{~K})$ using a $600^{\circ} \mathrm{C} / \mathrm{s}$ heating rate gave full density in $6 \mathrm{~min}$ [61]. This heating requires a current density of $13,000 \mathrm{~A} / \mathrm{cm}^{2}$. For a lower conductivity powder, $60 \mathrm{~nm}$ zirconia was heating with $120 \mathrm{~V} / \mathrm{m}$ voltage gradient from $40 \%$ green density to $850^{\circ} \mathrm{C}(1123 \mathrm{~K})$ to give full density in $5 \mathrm{~s}$ [62]. The benefit was from enhanced grain boundary heating. But these studies fail to give the whole story in terms of how to replicate the cycles. Besides incomplete reports, technological barriers and low productivity hinder widespread practical interest in spark sintering.

Metallic materials exhibit intense sintering when subjected to electrical discharge. Full density titanium is possible in short times with rapid heating, direct current flow, in time-temperature-pressure combinations that seem reasonable based on existing sintering models. However, graphite tooling contaminates some materials. For ceramic materials the electrical current concentrates in die, giving rapid hot pressing with no benefit over hot pressing where there is no electrical current [63-64]. So, outside diamond composites, spark sintering is awaiting some findings that show significant gains over that possible with other approaches.

\subsection{Plasma Discharge}

Similar to microwave heating, plasma discharges induce rapid heating [65]. Plasma discharge heating has been applied to diamond composites [66] and several ceramics such as $\mathrm{UO}_{2}, \mathrm{Al}_{2} \mathrm{O}_{3}, \mathrm{SiC}, \mathrm{MgO}$, and $\mathrm{ZrO}_{2}$ [67-71]. Densification is rapid, for example $99 \%$ density is attained for $50 \mathrm{~nm}$ alumina within $1 \mathrm{~min}$.

In plasma heating, the current-voltage situation is the 
opposite from electric current heating; plasma discharge relies on a high voltage and low current. In many cases the plasma is generated by a microwave or induction field acting on a low pressure gas. The residual gas is stripped of electrons and accelerated through a voltage gradient to impact the plasma on the powder compact. Polyatomic gases, such as nitrogen or hydrogen, are most common. The general sense is the plasma assists densification largely due to the steep concentration gradient inducing vacancy flow during surface heating.

Plasma sintering delivers a higher sintered density at intermediate temperatures compared to conventional sintering, but at peak sintering temperatures there is less advantage. Like microwave heating, plasmas drive rapid heating. So far it is best applied to continuous rod or tube sintering. Single compacts are usually under $1 \mathrm{~cm}^{3}$ in volume. Although the heating rate is impressive compared with other technologies, the throughput is under 1 $\mathrm{kg} / \mathrm{h}$.

\subsection{Microwave}

The advent of low cost microwave ovens at $2.45 \mathrm{GHz}$ frequency corresponding to $122 \mathrm{~mm}$ wavelength generated interest in microwave sintering. Reports emerged in the early $1980 \mathrm{~s}$ on $\mathrm{B}_{4} \mathrm{C}$ gave $95 \%$ density in $12 \mathrm{~min}$ of microwave heating [72]. It is most effective when the microwave directly couples to the green compact [73]. The approach has marched through demonstrations on many systems, resulting in considerable literature [74-79].

A home microwave oven is modified for sintering as

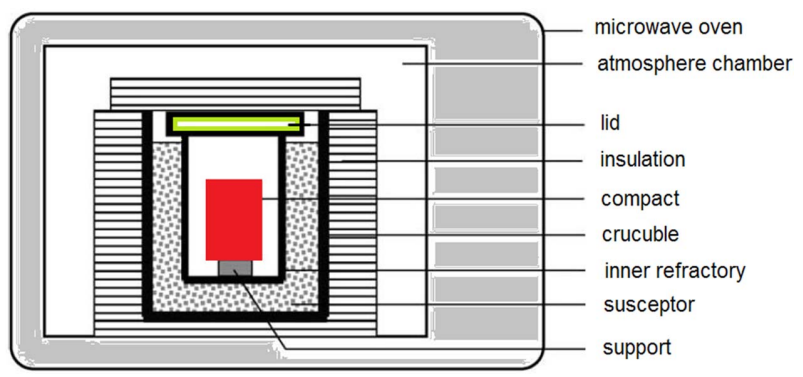

Fig. 3. Microwave sintering is possible in a home microwave oven if the heat is properly managed. Sketched here is a profile of the microwave oven containing a coffin of insulation board to contain the radiant energy emitted from the compact. A susceptor powder (usually SiC) is packed inside to absorb the microwave energy and the powder compact is either embedded in the susceptor of packaged in a crucible inside the susceptor. illustrated in Fig. 3. The powder compact is positioned in the cavity and surrounded by protective refractory ceramic and susceptor (usually silicon carbide). Microwave energy heats the susceptor holding the compact. Sintering of small samples within $2 \mathrm{~min}$ is possible. For metals, the chamber is flooded with nitrogen or argon. To avoid damage to the oven, an outer layer of ceramic insulator encapsulates the sample to contain the heat. High green density compacts swell during heating, so a porous green body is required to evaporate impurities during heating.

Heating by direct coupling of the powder compact depends on the dielectric behavior of the material. Dielectric constants for insulators range from 1600 for $\mathrm{BaTiO}_{3}$ to 10 for $\mathrm{MgO}$ and $\mathrm{Al}_{2} \mathrm{O}_{3}$, to 2 for polymers. A measure of effective polarization in an oscillating field is given by the loss tangent; a low loss tangent means the microwave passes through the material without heating. For many materials at low temperatures the loss tangent is low, but increases at high temperatures.

Penetration depths for ceramics are often large and direct coupling is difficult. As temperature increases the penetration depth decreases. For a given material, a critical condition occurs during heating where absorption becomes rapid and temperature increases quickly. To smooth out the nonlinear coupling, especially at low temperatures, susceptors are used to absorb the microwave energy. The hot susceptor transports heat to the powder compact.

The wave pattern in the microwave cavity determines the uniformity of heating. Multiple-mode cavities avoid hot spots, meaning the cavity size is large compared to the wavelength of the electromagnetic field. For uniform production, the sample and cavity sizes are matched to ensure uniform heating, although the motion of the sample in the field distorts the heating uniformity. Since large components exhibit uneven heating, microwave sintering is restricted to small components where internal and surface heating remain in balance to avoid distortion or defects. It is common to see cracking with high heating rates. To minimize damage the protocol is to sinter one compact at a time. Thus, a production microwave furnace operates on a continuous sequence of steps as illustrated in Fig. 4. Microwave energy is delivered to one component at a time and the crucibles act as susceptors 


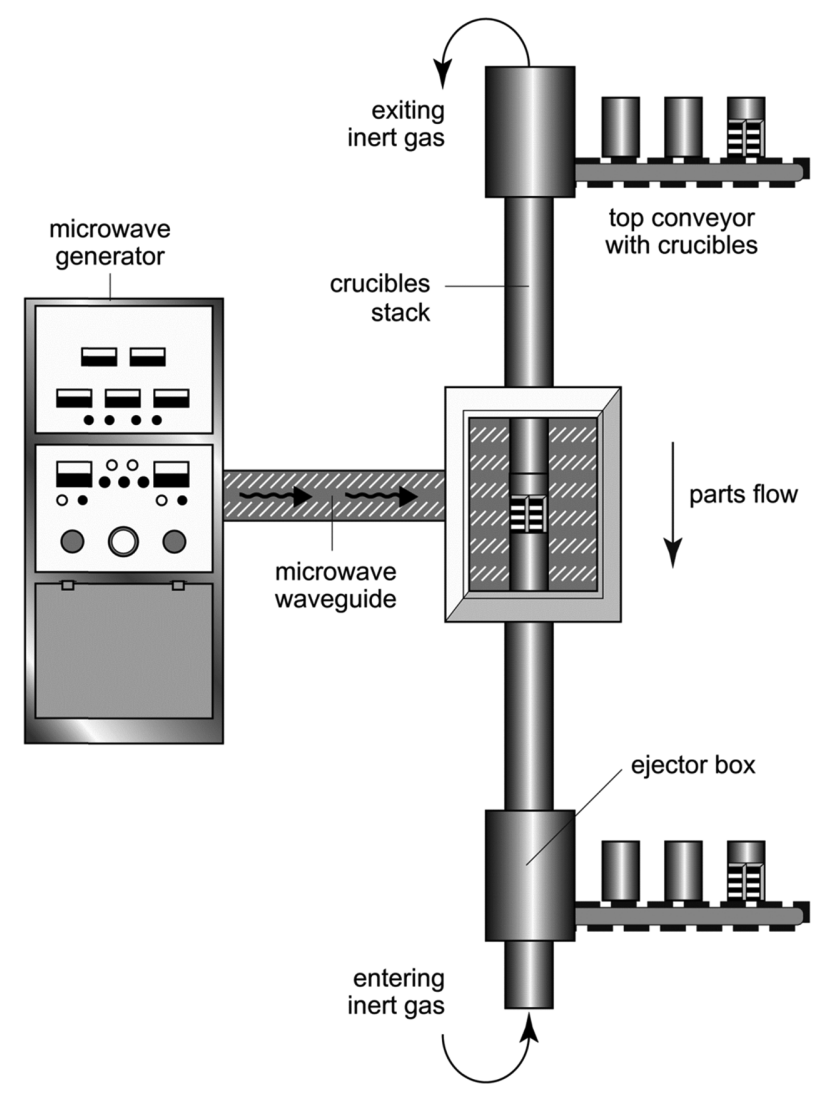

Fig. 4. Outline of a production microwave sintering furnace, where one compact at a time passes into the microwave zone. An automated elevator system conveys the susceptor crucibles into the microwave. In this unit, reaching $1400^{\circ} \mathrm{C}$ $(1673 \mathrm{~K})$, the cycle time was 8 min per compact.

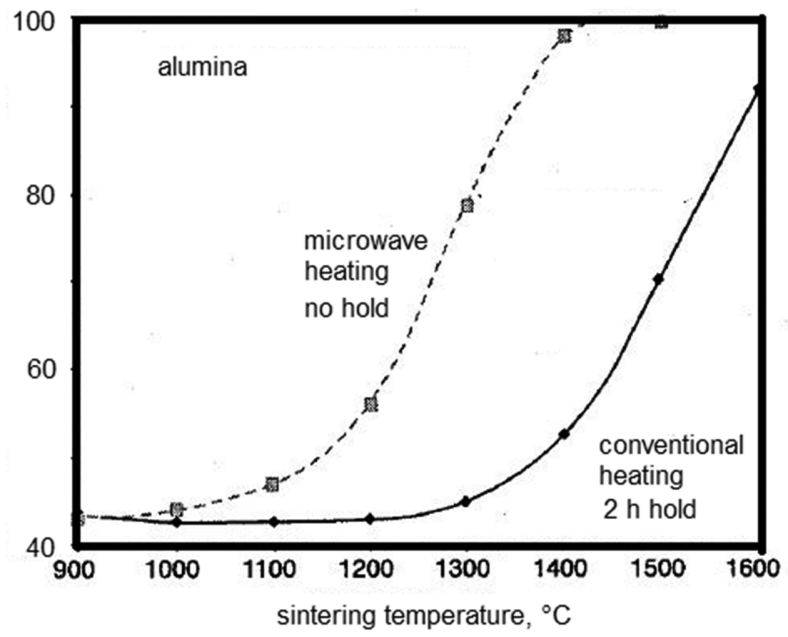

Fig. 5. Sintered density of alumina versus the peak temperature for microwave heating (no hold) and conventional heating ( 2 $h$ hold) [76].

when passing through the microwave.

Early demonstrations of microwave sintering on laboratory samples are impressive. Fig. 5 plots sintered density versus peak temperature for alumina. Small disk samples were processed by both microwave and conventional sintering, where the microwave had zero hold time at temperature and the conventional cycle relied on $2 \mathrm{~h}$ at temperature. Substantial density gains are evident with microwave sintering in shorter cycles, but explanation on why this is happening is elusive. In tests on aluminum, the microwave and conventionally sintered properties were similar. In microwave sintering of a 93 wt.\% tungsten heavy alloy, the sintered tensile strength is $805 \mathrm{MPa}$ with $11 \%$ elongation [80] while the conventionally processed material reaches $930 \mathrm{MPa}$ with 30\% elongation [81]. Rapid microwave heating provided less impurity removal, so although the cycle is fast, the sintered product is inferior.

Speculation exists on a new sintering mechanism via microwave heating. Most likely grain boundary impurities preferentially interact with the microwave energy prior to solvation or dissolution into the bulk material, giving hot grain boundaries to facilitate diffusion. Generally, other than singular experiments without parallel controls of the same material, heating rate, and peak temperature, little evidence exists to invoke a new mechanism. In direct comparison of sintered steel processed at $1250^{\circ} \mathrm{C}$, the strength was $1.8 \%$ higher for microwave sintering, but that was due to a higher carbon $(0.81 \%$ versus $0.77 \%$ for conventional) due to more carbon loss during conventional heating [82]. Again this is confounded since there is no direct comparison at the same heating rate - in many trials it is the heating rate (possible with a dunk cycle) not microwave heating that makes a difference. In trials on zirconia involving microwave and dunk sintering, the sintered density showed no benefit from microwave heating.

Suggestions of improved energy efficient often fail to include energy loss from the microwave cavity. Higher properties after microwave sintering usually are based on multiple effects such as composition differences or cooling rate differences. For example, microwave sintered cemented carbides (WC-Co) are harder due to rapid cooling when sintering one compact at a time. This is not a direct effect of microwave heating. The same cooling comes with rapid compact extraction from a conventional furnace. Microwave heating only delivers one compact at a time and is not well matched to industrial 


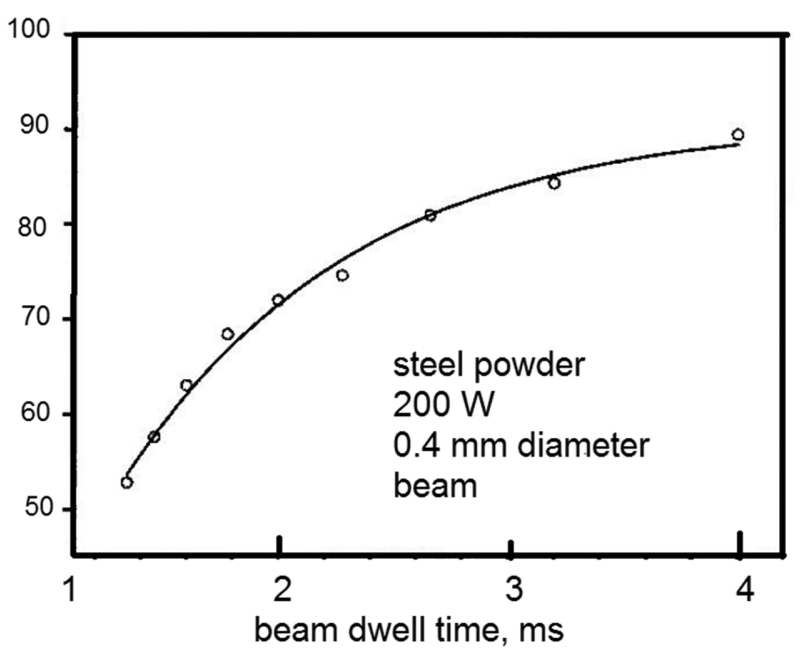

Fig. 6. Density (\%) of laser sintered steel powder in a $200 \mathrm{~W}$ beam of $0.4 \mathrm{~mm}$ diameter, giving the sintered density as a function of the beam dwell time [83]. For these experiments the samples were small to with no collateral heating from neighboring beam passes. In practice there will be neighboring passes and further heating from each powder layer as well.

sintering rates of $100 \mathrm{~kg} / \mathrm{h}$ in conventional furnaces.

\subsection{Light - Lasers and Infrared Heating}

Localized heat from a laser beam is employed in welding and surface glazing. Because of the power concentration, lasers provide rapid sintering in small areas. For example, Fig. 6 plots density data for a laser sintered steel powder processed using a $0.4 \mathrm{~mm}$ diameter $200 \mathrm{~W}$ laser beam [83]. The longer the dwell time the higher the sintered density, although the effect diminishes after 2 ms. Even so, initial sintering is rapid. Infrared heating is similar, except the light is not focused to one spot. It is suitable for thin structures [84]. Wide area heating units delivering $9 \mathrm{~kW} / \mathrm{cm}^{2}$ are used for sintering surface coatings.

An important use for laser sintering is additive manufacturing, where x-y stage motion is coordinated with the layering and laser sintering to build a three-dimensional object, one slice at a time [85]. Additive manufacturing started in the 1980 s, initially with paper and plastic, moving to metals in the early $1990 \mathrm{~s}$, and more recently to ceramics [86]. A schematic of laser sintering for additive manufacturing is given in Fig. 7. An image of the desired object is converted into a stack of two-dimensional layers. Powder is placed on the x-y stage and the laser beam (or even electron beam) is applied to induce sintering. In recent units the heating is to the semisolid temperature

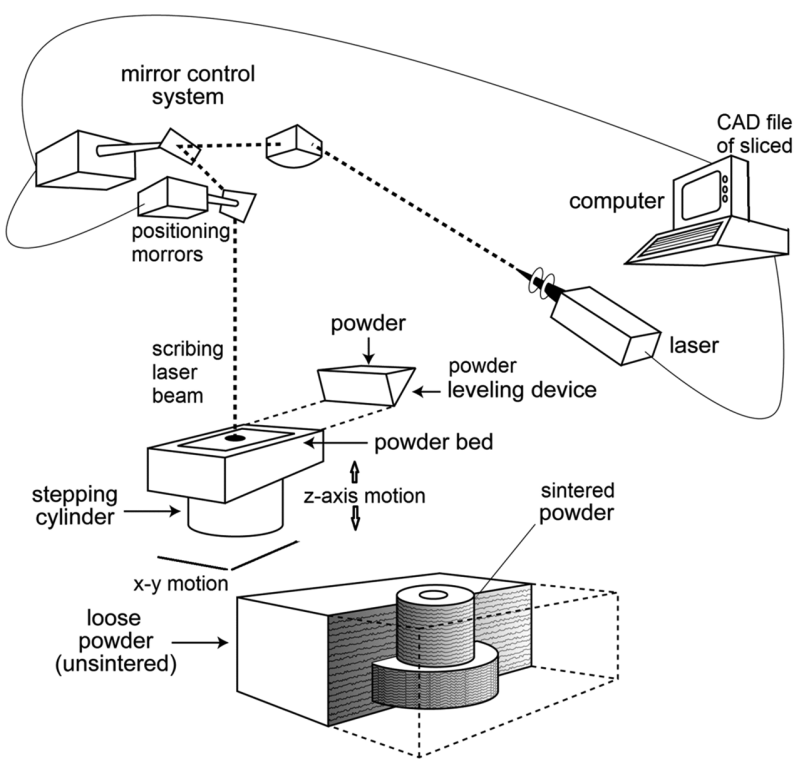

Fig. 7. Component additive manufacturing in laser sintering relies on a computer design file that is sliced to determine the laser rastering over the powder bed. A three-dimensional object is grown by repeated layering and laser rastering. The unsintered powder is removed after the build process.

range. Laser positioning is coordinated to the projected solid $x-y-z$ coordinate. After each layer is processed, a fresh layer of powder is added and the cycle repeated. The time to build an object is slow, although the local sintering rate is rapid. Beam energy, velocity, and diameter determine the input energy, some of which is reflected off the powder, while the heat capacity of the powder and the sintering temperature determine the build rate.

After each sintering scan a fresh layer of powder is introduced. This powder is then sintered to the underlying layer. The time-temperature-particle size and related factors follow traditional sintering models [87]. By proper coordination to a computer image, the final sintered object has the shape complexity of the desired object. Unfortunately, the layers are formed in steps, so rounded surfaces take on a stair step character as shown in Fig. 8. Laser sintering units range from $8 \mathrm{~W}$ to $14 \mathrm{~kW}$ beams with diameters in the 0.4 to $1 \mathrm{~mm}$ range. For a plastic powder $8 \mathrm{~W}$ is effective while for high temperature titanium or similar materials the high power units are required [88-89]. Heating rates over $40^{\circ} \mathrm{C} / \mathrm{s}$ are used on metal powders. Efforts with zirconia require preheating to $800^{\circ} \mathrm{C}(1073 \mathrm{~K})$ prior to laser heating to $1700^{\circ} \mathrm{C}(1973$ $\mathrm{K})$. If the laser traverse rate is too fast, then the powder fails to sinter and if the traverse rate is too slow the spe- 


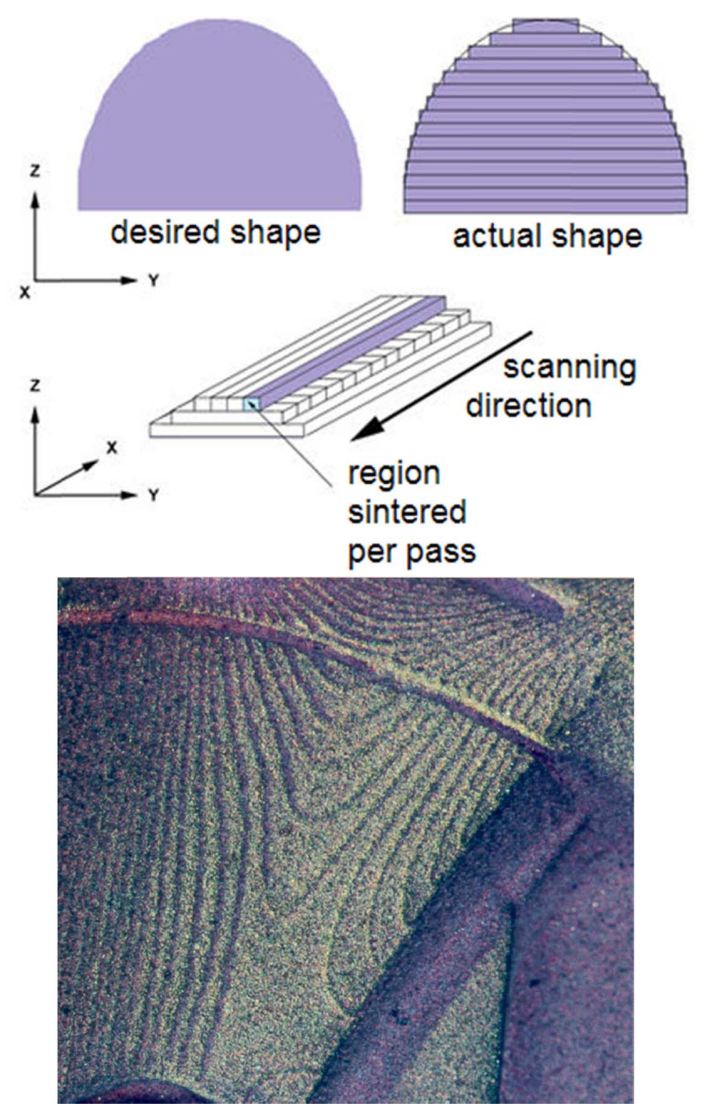

Fig. 8. Additive manufacturing based on rapid sintering under a laser beam forms stair-step layer approximations to rounded surfaces, a) illustrates the concept and b) is a photograph of a curved surface with terraces.

cial resolution is lost due to heat spreading. One option is to apply sufficient laser heating for presintering followed by a traditional sintering run. Layer thickness is usually 0.1 to $1 \mathrm{~mm}$ since more power is required in the laser. The sintering energy falls with the inverse fifth power of the layer depth. Consequently, surface heating is high but heat transport through the powder limits sintering depth. This results in substantial gradients in the sintered microstructure, density, and dimensions, often requiring overheating of the top surface to induce sintering at the bottom of the layer.

\subsection{Induction}

Hot pressing has long relied on induction heating where a high frequency alternating current is used to induce eddy currents in graphite tooling to rapidly heat the compact. Rapid heating is possible even if no pressure is applied, and demonstrations with nanoscale powders have reached 15 to $20^{\circ} \mathrm{C} / \mathrm{s}$ [90]. With supplemental pressure, slightly

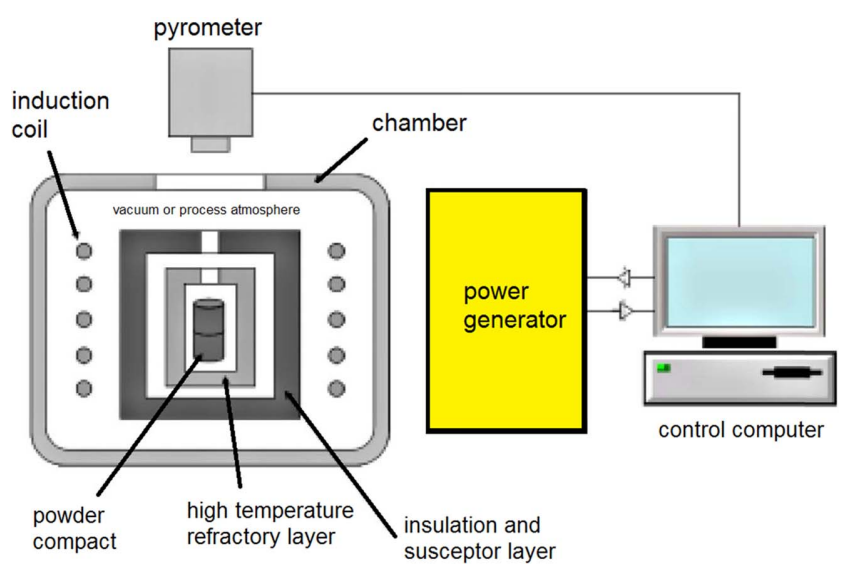

Fig. 9. Induction heating relies on a water chilled copper coil that delivers a high frequency magnetic field to the powder compact. Each cycle induces eddy current heating in the powder compact or in the susceptor layer.

slower heating occurs since there is the added thermal mass of the tooling. Heating cycles are a few minutes long, but cooling is slower.

Induction sintering surrounds the compact with a conductive coil that carries a high frequency alternating current. One design is sketched in Fig. 9, using a water cooled outer copper coil and graphite susceptor. Current direction reversal in the coil changes the magnetic field polarity, reversing the eddy current direction. Resistance to current passage causes heating. Frequencies runs from $50 \mathrm{~Hz}$ up to $50 \mathrm{kHz}$ and some efforts have gone higher into the $\mathrm{MHz}$ range. Atmosphere control is possible inside the refractory crucible. The current in the conduction coil creates a magnetic field that induces eddy currents in the susceptor and powder compact. For nonconductors, a susceptor is needed to generate heat and graphite proves most useful. The inductor coil design is customized to the material, sample size, and frequency. Most trials rely on small components, cylinders or disks of $12 \mathrm{~mm}$ diameter are common. Heat transfer for induction heating is 3000 times faster than radiant heating, although it is largely surface heating and is restricted to one part at a time. An outer chamber contains the process atmosphere or holds a vacuum. Most trials find best properties at slower heating rates and shorter hold times [91-92].

The penetration depth limits the compact size since surface heating causes cracking. Penetration depths up to $100 \mathrm{~mm}$ are possible at room temperature, but as temperature increase the penetration depth decreases. In spite of 


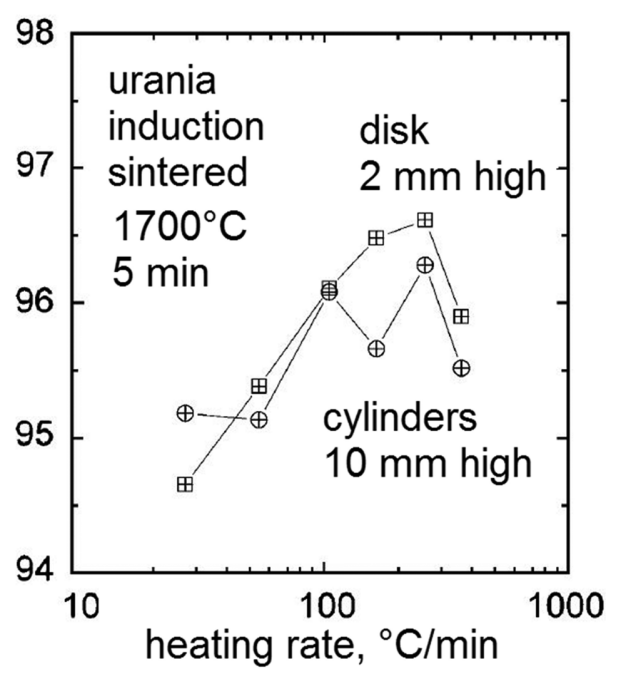

Fig. 10. Induction sintered urania $\left(\mathrm{UO}_{2}\right)$ at $1700^{\circ} \mathrm{C}(1973 \mathrm{~K})$ giving the sintered density for two test geometries after $5 \mathrm{~min}$ holds at the sintering temperature [93]. At heating rates over approximately $5^{\circ} \mathrm{C} / \mathrm{s}\left(300^{\circ} \mathrm{C} / \mathrm{min}\right)$ the deity degrades.

the rapid sintering, the technique is used infrequently in practice, largely because of low productivity associated with sintering a single compact at a time. On the other hand, induction is widely employed in hot pressing with graphite tooling.

Sintering densification and properties, as well as defect avoidance, is best with about $20^{\circ} \mathrm{C} / \mathrm{s}$ or less heating rate. Fig. 10 illustrates this optimization for sintering $10 \mathrm{~mm}$ diameter urania $\left(\mathrm{UO}_{2}\right)$ disks and cylinders [93]. Different heating rates were used to the peak temperature of $1700^{\circ} \mathrm{C}(1973 \mathrm{~K})$ which was held for $5 \mathrm{~min}$. Faster heating cracked the compacts. For materials that tend to outgas during heating, it is imperative to have intermediate temperature holds for volatilization of the species prior to rapid heating. Several powder systems are responsive to rapid induction heating [94-97]. In experiments on WC$15 \mathrm{Co}$, sintering to $97 \%$ density was possible in $1 \mathrm{~min}$ using $50 \mathrm{kHz}$ frequency at $15 \mathrm{~kW}$, with heating reported at $20^{\circ} \mathrm{C} / \mathrm{s}$. Curiously, when compared to spark sintering at $60 \mathrm{MPa}$, induction hot pressing gives a higher hardness for WC-Co.

\section{Supplemental Pressure}

As with traditional sintering, supplemental pressure improves particle bonding and densification, even during rapid heating. An example of the pressure effect is plotted in Fig. 11 for zirconia heated at $200^{\circ} \mathrm{C} / \mathrm{min}$ or $3 / 3^{\circ} \mathrm{C} /$

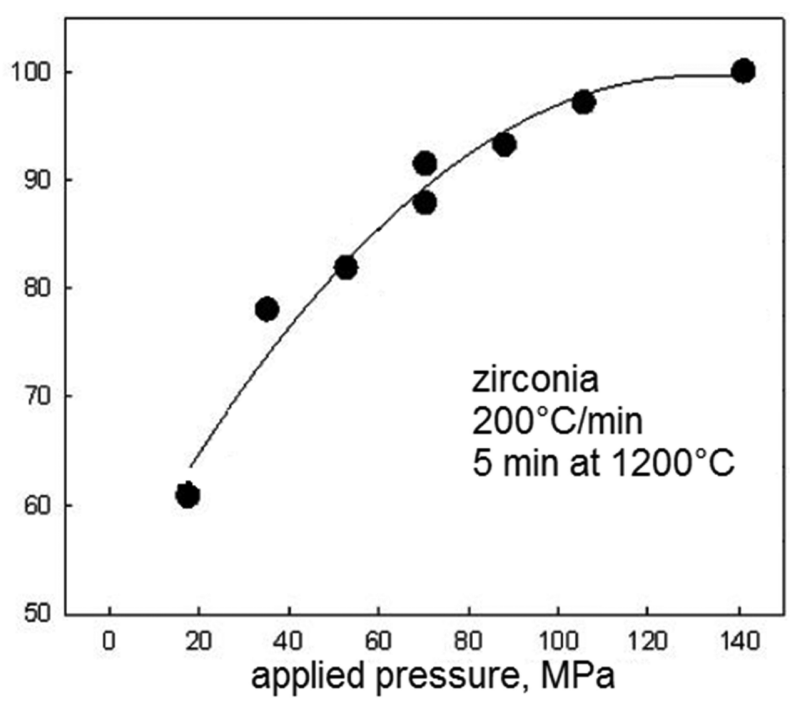

Fig. 11. Spark sintering of zirconia using a $3.3^{\circ} \mathrm{C} / \mathrm{s}\left(200^{\circ} \mathrm{C} /\right.$ min) heating rate to $1200^{\circ} \mathrm{C}(1473 \mathrm{~K})$ with a 5 min hold [98]. Sintered density increases with the applied pressure, while the grain size remains relatively constant near $100 \mathrm{~nm}$.

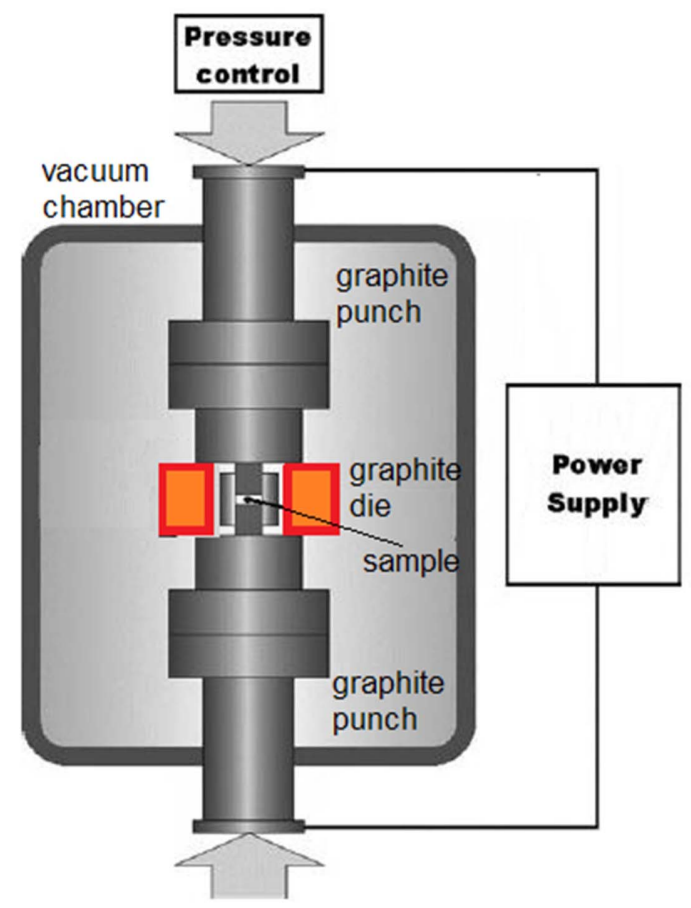

Fig. 12. Outline of the spark sintering process with an applied pressure. The power supply provides both direct current and alternating current heating of the graphite and powder (if the powder is conductive). Pulsed direct current heating is most typical. External force is generated from two opposed graphite punches. For nonconductive powder, current passes only in the tooling, but for a conductive powder the current also passes through the powder.

s. The plot shows sintered density using a 5 min consolidation cycle with a peak temperature of $1200^{\circ} \mathrm{C}(1473 \mathrm{~K})$ 
Table 1. Comparative Properties for $4 \mu \mathrm{m}$ Steel by Sintering, Hot Isostatic Pressing, and Rapid Hot Isostatic Pressing

\begin{tabular}{lccc}
\hline \hline Consolidation route & $\begin{array}{c}\text { Traditional } \\
\text { sinter }\end{array}$ & $\begin{array}{c}\text { Hot isostatic } \\
\text { press }\end{array}$ & $\begin{array}{c}\text { Rapid hot } \\
\text { isostatic press }\end{array}$ \\
\hline First sinter & $1300^{\circ} \mathrm{C}$ & $1200^{\circ} \mathrm{C}$ & $1200^{\circ} \mathrm{C}$ \\
& $60 \mathrm{~min}$ & $60 \mathrm{~min}$ & $60 \mathrm{~min}$ \\
& vacuum & vacuum & vacuum \\
Second sinter & None & $605^{\circ} \mathrm{C}$ & $805^{\circ} \mathrm{C}$ \\
& & $200 \mathrm{MPa} \mathrm{Ar}$ & $500 \mathrm{MPa} \mathrm{Ar}$ \\
Density, \% & 96.2 & 98.9 & 99.5 \\
Tensile strength, MPa & 498 & 385 & 732 \\
Ductility, \% & 5.4 & 39.0 & 23.4 \\
Hardness, HRB & 85.1 & 90.2 & 91.8 \\
\hline
\end{tabular}

[98]. Noteworthy is the lack of grain size enlargement during these cycles. These use electrical discharge though the graphite tooling surrounding the powder while applying pressure through upper and lower punches, as illustrated in Fig. 12.

It is reasonable to expect the combination of rapid heating and supplemental pressure produce rapid densification. Thus, an array of technologies emerge - such as microwave hot pressing, exothermic hot pressing, reactive hot isostatic pressing, spark sintering, induction hot pressing, quick hot isostatic pressing, and rapid omnidirectional compaction. This is an intersection of sintering with high strain rate material forming technologies that revive earlier ideas [99-110]. As a demonstration of the benefits from rapid pressure-assisted consolidation, Table 1 compares the mechanical properties of traditionally sintered, hot isostatically pressed, and rapidly consolidated 4 $\mu \mathrm{m}$ steel powder. The rapid consolidation occurs by dunk heating the material and injecting liquid argon into the closed pressure vessel, generating a short pressure pulse. The property advantages are quite evident.

Pressure aids consolidation, but the pressurization pulse needs to happen after the heating pulse. This delay prevents inhomogeneities in the product microstructure. But high strain rates can cause component cracking. The difficulty in controlling and scaling up the rapid heating processes is exacerbated when an external pressure is applied.

\section{Conclusions}

Rapid heating provides new sintering trajectories with improved density and grain size combinations. Several approaches have reached the pilot stage and show a few characteristic points:

- the components need to be small (under $10 \mathrm{~mm}$ ) to respond to rapid energy input

- the powders need to be small, and even nanoscale, to undergo rapid densification

- heating rates tend to optimize at levels near $20^{\circ} \mathrm{C} / \mathrm{s}$

- long hold times and high peak temperatures induce a loss of density (swelling)

- warpage, cracking, and other defects are common, especially at high heating rates

- powders must be degassed and all polymers removed prior to rapid heating

- most approaches sinter one compact at a time giving 1 to 4 compacts per hour

- from the capital cost viewpoint, most approaches are more expensive than traditional sintering furnaces

- production cost is also higher compared to conventional sintering.

Much effort is devoted to developing new sintering schemes and often these return to concepts demonstrated long ago; spark sintering was applied in 1900 as one example. Rapid sintering results in significant density and microstructure gains in short processing times. This is most useful for metastable materials - diamond composites, thermoelectric compounds, amorphous metals, and nanoscale powders. For mainstream powder metallurgy materials, such as ferrous automotive alloys, the gains demonstrated from rapid sintering are matched by conventional sintering using new compositions. Seemingly every advance by rapid sintering results in a shift to a new alloy or composition to deliver equivalent properties within the context of conventional heating. Thus, rapid heating is a "push technology", initiating improvements in conventional sintering without moving into widespread utilization.

Green powder structures are poor heat conductors. Consequently, rapid heating induces thermal gradient driven diffusion that is supplements the normal sintering stress. Rapid heating also generates stresses that activate dislocation events. But for components over about 10 $\mathrm{mm}$ in thickness, these same thermal stresses cause cracking or warpage. Such warpage gives "potato chip" geometries similar to that seen in Fig. 13. What started as a flat material warped during rapid heating, so dimen- 


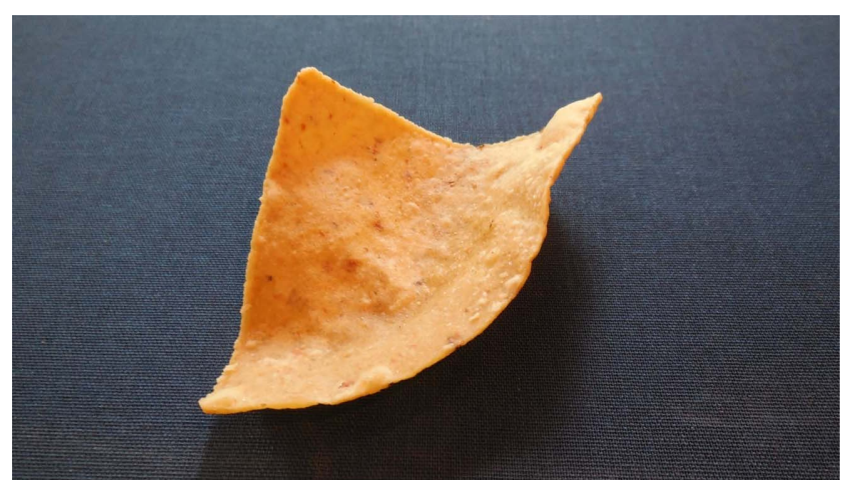

Fig. 13. Picture of the extensive warping (toward the heat source) encountered in rapid heating, in what is termed the potato chip shape. Such loss of shape is the most difficult aspect of rapid heating.

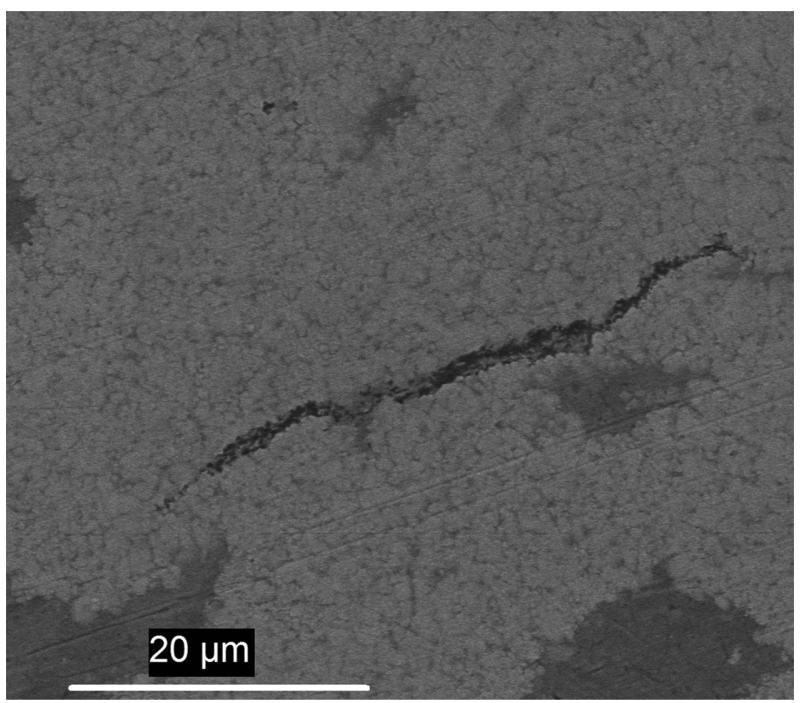

Fig. 14. An example flaw and heterogeneous microstructure found in spark sintered tungsten-copper, where the pressure and short cycle time created a defective microstructure.

sional control is a severe challenge with rapid heating.

Most of the efforts to scale-up rapid heating to commercial practice are unsuccessful. Pressurized direct current approaches are successful because the applied pressure holds the component into final shape, albeit a simple shape. The rapid sintering routes are still expensive and difficult to control. Defects are common, such as the internal flaw captured in Fig. 14 from a spark sintered W-Cu heat sink. There is a further problem of poor homogeneity since liquid flow is limited by the short cycle and applied pressure. The one exception where rapid heating is moving forward is additive manufacturing via laser sintering. This approach is making inroads into production situations, such as fabrication of custom- ized dental crowns, medical restorations, and aircraft and automotive components.

Rapid heating opens new microstructure and property combinations due to minimized time for coarsening. However, sintering one compact at a time is cost restrictive. Traditional sintering furnaces reach upwards of tons per day in output. So far this level of productivity is not demonstrated using rapid heating schemes. Near-term research on rapid heating concepts need to assess any sintering mechanism changes in comparisons, while attending to optimized cycles, specification of proper powders, isolation of impurities, and careful audits to assess property and microstructure gains versus traditional cycles. In the end, traditional sintering furnaces might be designed with faster cycles without the need for microwave, induction, electric current, plasma, or other novel heating approaches.

\section{References}

[1] W. L. Voelker: U. S. Patent 660,475, issued 23 October 1900.

[2] W. L. Voelker: GB Patent 6149, issued 10 February 1900.

[3] P. Schwarzkopf: Powder Metallurgy Its Physics and Production, Macmillan, New York, NY, 1947.

[4] W. D. Coolidge: U. S. Patent 1,077,674, issued 5 November 1913.

[5] F. V. Lenel: Trans. TMS-AIME, 203 (1955) 158.

[6] J. Li, Y. Ye: J. Amer. Ceram. Soc., 89 (2006) 139.

[7] Z. A. Munir, U. Anselmi-Tamburini and M. Ohyanagi: J. Mater. Sci., 41 (2006) 763.

[8] S. Grasso, Y. Sakka and G. Maizza: Sci. Tech. Adv. Mater., 10 (2010) 053001.

[9] P. Vergnon, M. Astier and S. J. Teichner: Fine Particles, W. E. Kuhn (ed.), Electrochemical Society, Princeton, NJ, 1974, 299-307.

[10] M. Cologna, J. S. C. Francis and R. Raj: J. Euro. Ceram. Soc., 31 (2011) 2827.

[11] D. Beruto, R. Botter and A. W. Searcy: J. Amer. Ceram. Soc., 72 (1989) 232.

[12] A. W. Searcy and D. Beruto: Science of Ceramics, 14, D. Taylor (ed.), Institute of Ceramics, Stokes-on-Trent, UK (1988) 1.

[13] C. S. Morgan: High Temp. - High Press., 3 (1971) 317.

[14] M. P. Harmer and R. J. Brook: J. Brit. Ceram. Soc., 80 (1981) 147.

[15] R. M. Young and R. McPherson: J. Amer. Ceram. Soc., 72 (1989) 1080.

[16] A. W. Searcy: J. Amer. Ceram. Soc., 70 (1987) C61.

[17] M. P. Kassarjian, B. H. Fox and J. V. Biggers: J. Amer. Ceram. Soc., 68 (1985) C140.

[18] R. H. R. Castro, G. J. Pereira and D. Gouvea: Proceed- 
ings of the 4th Inter. Conference on Science, Technology and Applications of Sintering, D. Bouvard (ed.), Institut National Polytechnique de Grenoble, Grenoble, France (2005) 394.

[19] D. M. Hulbert, A. Anders, J. Andersson, E. J. Lavernia and A. K. Mukherjee: Scripta Mater., 60 (1985) 835.

[20] D. C. Blaine, R. M. German and S. J. Park: Adv. Powder Metall. Part. Mater. - 2005, MPIF, Princeton, NJ (2005) 1.29 .

[21] D. L. Johnson: Sintering and Heterogeneous Catalysis, G. C. Kuczynski, A. E. Miller and G. A. Sargent (eds.), Plenum Press, New York, NY (1984) 243.

[22] C. E. G. Bennett, N. A. McKinnon and L. S. Williams: Nature 217 (1968) 1287.

[23] G. E. Tardiff: Inter. J. Powder Metall., 5(4) (1969) 29.

[24] K. Upadhya: J. Metals, 39 [12] (1987) 11.

[25] P. C. Kong, Y. C. Lau, E. Pfender, K. McHenry, W. Wallenhorst and B. Koepke: Ceramic Trans., 1, G. L. Messing, E. R. Fuller, and H. Hausner (eds.), American Ceram. Soc., Westerville, OH (1987) 939.

[26] M. Eriksson, Z. Shen and M. Nygren: Powder Met., 48 (2005) 231.

[27] C. Feng, H. Qiu, J. Guo, D. Yan and W. A. Schulze: J. Mater. Synth. Proc., 3 (1995) 25.

[28] C. You, D. Jiang and S. Tan: J. Amer. Ceram. Soc., 87 (2004) 759.

[29] C. Feng, E. Shi, J. Guo, D. Yan and W. A. Schulze: J. Mater. Synth. Proc., 3 (1995) 31.

[30] P. Vergnon, M. Astier and S. J. Teichner: Sintering and Related Phenomena, G. C. Kuczynski (ed.), Plenum Press, New York, NY (1973) 301.

[31] D. J. Chen and M. J. Mayo: J. Amer. Ceram. Soc., 79 (1996) 906.

[32] D. H. Kim and C. H. Kim: J. Amer. Ceram. Soc., 75 (1992) 716.

[33] J. B. Holt, D. D. Kingman and G. M. Bianchini: Mater. Sci. Eng., 71 (1985) 321.

[34] R. L. Coble: Sintering - Theory and Practice, D. Kolar, S. Pejovnik and M. M. Ristic (eds.), Elsevier Scientific, Amsterdam, Netherland (1982) 145.

[35] A. Varma: Chem. Eng. Edu., (2001) [4] 14.

[36] H. Hanado and Y. Hiraoka: Mater. Trans., 48 (2007) 775.

[37] A. Bose, B. H. Rabin and R. M. German: Powder Metall. Inter., 20(3) (1988) 25.

[38] S. Takeda: Sintering '87, 2, S. Somiya, M. Shimada, M. Yoshimura and R. Watanabe (eds.), Elsevier Applied Sci., London, UK (1988) 1076.

[39] A. Sawaoka and S. Saito: Ferrites, Y. Hoshino, S. Iida and M. Sugimoto (eds.), University Park Press, Baltimore, MD (1970) 102.

[40] L. Gao, Z. Shen, H. Miyamoto and M. Nygren: J. Amer. Ceram. Soc., 82 (1999) 1061.

[41] T. Nagae, M. Yokota, M. Nose, S. Tomida, T. Kamiya and S. Saji: Mater. Trans., 43 (2002) 1390.

[42] M. Suganuma, Y. Kitagawa, S. Wada and N. Murayama: J. Amer. Ceram. Soc., 86 (2006) 387.

[43] J. Zhang, A. Zavaliangos and J. Groza: P/M Sci. Tech. Briefs, 5(4) (2003) 5.

[44] J. F. Garay: Ann. Rev. Mater. Res., 40 (2010) 445.

[45] Z. A. Munir, D. V. Quach and M. Ohyanagi: J. Amer. Ceram. Soc., 94 (2011) 1.

[46] S. T. Lin and R. M. German, Metall. Trans., 1990, 21A, 2531-2538.

[47] E. A. Olevsky, S. Kandukuri and L. Froyen: J. Appl. Phys., 102 (2007) 114913.

[48] A. Accary and R. Caillat: J. Amer. Ceram. Soc., 45 (1962) 347.

[49] L. Rangaraj, S. J. Suresha, C. Divakar and V. Jayaram: Metall. Mater. Trans., 39A (2008) 1496.

[50] J. C. Murray and R. M. German: Adv. Powder Metall. Particulate Mater., 9, J. M. Capus and R. M. German (eds.), MPIF, Princeton, NJ (1992) 295.

[51] A. L. Chamberlain, W. G. Fahrenholtz and G. E. Hilmas: J. Amer. Ceram. Soc., 89 (2006) 3638.

[52] A. Sewchurran and L. A. Cornish: Sintering Sci. and Tech., R. M. German, G. L. Messing and R. G. Cornwall (eds.), Pennsylvania State University, State College, PA (2000) 63.

[53] L. Chen and E. Kny: Inter. J. Refract. Metals Hard Mater., 18 (2000) 163.

[54] E. Paransky, E. Y. Gutmanas, I. Gotman and M. Koczak: Metall. Mater. Trans., 27A (1996) 2130.

[55] L. Rangaraj, C. Divakar and V. Jayaram: J. Amer. Ceram. Soc., 87 (2004) 1872.

[56] D. R. Campbell and H. B. Huntington: Phys. Rev., 179 (1069) 609.

[57] J. M. Frei, U. Anselmi-Tamburini and Z. A. Munir: J. Appl. Phys., 101 (2007) 114914.

[58] Y. Aman, V. Garnier and E. Djurado: J. Mater. Sci., 47 (2012) 5766.

[59] C. M. Hsu, D. S. H. Wong and S. W. Chen: J. Appl. Phys., 102 (2007) 023715.

[60] G Davies and T. Evans: Proc. Royal Soc. London A, 328 (1972) 413.

[61] K. Feng, Y. Yang, B. Shen, L. Guo and H. He: Powder Metall., 48 (2005) 203.

[62] M. Cologna, B. Rashkova and R. Raj: J. Amer. Ceram. Soc., 93 (2010) 3556.

[63] B. Bernard-Granger, A. Addad, G Fantozzi, G Bonnefont, C, Guizard and D. Vernat: Acta Mater., 58 (2010) 3390.

[64] G Bernard-Granger, N. Monchalin and C. Guizard: Mater. Lett., 62 (2008) 4555.

[65] L. G Cordone and W. E. Martinsen: J. Amer. Ceram. Soc., 55 (1972) 380 .

[66] B. Twomey, A. Breen, G Byrne, A. Hynes and D. P. Dowling: Powder Metall., 53 (2010) 188.

[67] G. Thomas, J. Freim and W. Martinsen: Trans. Amer. 
Nucl. Soc., 17 (1973) 177.

[68] D. L. Johnson and R. A. Rizzo: Ceram. Bull., 59 (1980) 467.

[69] E. L. Kemer and D. L. Johnson; Ceram. Bull., 64 (1985) 1132.

[70] S. Sano, K. Oda, Y. Shibasaki, T. Matayoshi, Y. Kayama, Y. Setsuhara and S. Miyake: J. Japan Soc. Powder Powder Metall., 41 (1994) 739.

[71] M. Ray, D. R. Sahu, S. K. Singhe, S. Verma and B. K. Roul; Mater. Chem. Phys., 10 (2008) 435.

[72] J. D. Katz, R. D. Blake, J. J. Petrovic and H. Sheinberg: Metal Powder Rept., 43 (1988) 835.

[73] J. D. Katz: Ann. Rev. Mater. Sci., 22 (1992) 153.

[74] D. E. Clark and W. H. Sutton: Ann. Rev. Mater. Sci., 26 (1996) 299.

[75] Y. V. Bykov, K. I. Rybakov and V. E. Semenov: J. Physics D: Appl. Phys., 34 (2001) R55.

[76] D. Agrawal: Sintering of Advanced Mater., Z. Z. Fang (ed.), Woodhead Publishing, Oxford, UK (2010) 222.

[77] S. Takayama, G. Link, S. Miksch, M. Sato, J. Ichikawa and M. Thumm: Powder Metall., 49 (2006) 274.

[78] G. F. Zu, I. K. Lloyd, Y. Carmel, T. Olorunyolemi and O. C. Wilson: J. Mater. Res., 16 (2001) 2850.

[79] S. D. Luo, C. L. Guan, Y. F. Yang, G. B. Schaffer and M. Quan: Metall. Mater. Trans., 44A (2013) in press.

[80] A. Upadhyaya, S. K. Tiwari and P. Mishra: Scripta Mater., 56 (2007) 5.

[81] R. M. German: Powder Metallurgy and Particulate Materials Processing, MPIF, Princeton, NJ (2005).

[82] M. J. Yang and R. M. German: Adv. Powder Metall. Part. Mater. - 1999, 1, MPIF, Princeton, NJ (1999) 3.207.

[83] A. Simchi, F. Petzoldt, H. Pohl and H. Loffler: P/M Sci. Tech. Briefs, 3 (2001) 5.

[84] J. D. K. Rivard, A. S. Sabau, C. A. Blue, D. C. Harper and J. O. Kiggans: Metall. Mater. Trans., 37A (2007) 1289.

[85] M. Agarwala, D. Bourell, J. Beaman, H. Marcus and J. Barlow: Rapid Proto. J., 1 (1995) 26.

[86] D. E. Bunnell, D. L. Bourell and H. L. Marcus: Adv. Powder Metall. Particulate Mater. - 1996, MPIF, Princeton, NJ (1996) 15.93.

[87] D. L. Bourell and J. J. Beaman: Mater. Processing and Interfaces, 1, Proceedings 141st Meeting the Minerals, Metals, and Mater. Society, Warrendale, PA (2012) 537.

[88] T. B. Sercombe: P/M Sci. Tech. Briefs, 3(6) (2001) 22.

[89] F. G. Arcella and F. H. Froes: J. Metals, May (2000) 28.

[90] H. C. Kim, I. J. Shon, J. K. Yoon, J. M. Doh and Z. A. Munir: Inter. J. Refractor Metals Hard Mater., 24 (2006) 427.

[91] M. Nakamura, N. Chida, T. Ohba and Y. Sugaya: J. Jap.
Soc. Powder Powder Metall., 46 (1999) 538.

[92] H. C. Kim, D. Y. Oh and I. J. Shon: Inter. J. Refract. Metals Hard Mater., 22 (2004) 197.

[93] H. H. Yang, Y. W. Kim, J. H. Kim, D. J. Kim, K. W. Kang, Y. W. Rhee, K. S. Kim and K. W. Song: J. Amer. Ceram. Soc., 91 (2001) 3202.

[94] W. Hermel, G Leitner and R. Krumphold: Powder Metall., 23 (1980) 130.

[95] M. Nakamura, H. Takahashi and Y. Sugaya: J. Jap. Soc. Powder Powder Metall., 49 (2002) 534.

[96] K. C. Kim, H. K. Park, I. K. Heong, I. Y. Ko and I. J. Shon: Ceram. Inter., 34 (2008) 1419.

[97] H. C. Kim, I. K. Jeong, I. J. Shon, I. Y. Ko and J. M. Doh: Inter. J. Refract. Metals Hard Mater., 25 (2007) 336.

[98] Z. A. Munir, U. Anselmi-Tamburini and M. Ohyanagi: J. Mater. Sci., 41 (2006) 763.

[99] C. G. Goetzel, Treatise on Powder Metallurgy, 1, InterScience Pub., New York, NY (1949) 259.

[100] Y. Miyamoto, M. Koizumi and O. Yamada: J. Amer. Ceram. Soc., 67 (1984) C224.

[101] H. L. Marcus, D. L. Bourell, Z. Eliezer, C. Persad and W. Weldon: J. Metals, 39 [12] (1987) 6.

[102] M. A. Vasilkovska, V. I. Kovtun, S. A. Firstov, A. L. Maistrenko, M. N. Pavlovskiy and V. V. Komissarov: Science of Sintering: Current Problems and New Trends, M. M. Ristic (ed.), Serbian Academy of Sci. and Arts, Beograd, Serbia (2003) 265.

[103] F. D. S. Marquis and A. Mahajan: Powder Mater.: Current Research and Industrial Practices III, F. D. S. Marquis (ed), The Minerals, Metals and Mater. Society, Warrendale, PA (2003) 141.

[104] Y. Murakoshi, M. Takahashi, K. Hanada, T. Sano and H. Negishi: J. Jap. Soc. Powder Powder Metall., 48 (2001) 565.

[105] B. K. Yen, T. Aizawa and K. Kihara: J. Amer. Ceram. Soc., 81 (1998) 1953.

[106] J. H. Lee, N. N. Thadhani and H. A. Grebe, Metall. Mater. Trans., 27A (1996) 1749.

[107] I. Sato, A. Hibino and H. Negishi: J. Jap. Soc. Powder Powder Metall., 42 (1995) 283.

[108] T. Aizawa, S. Kamenosono, J. Kihara, T. Kato, K. Tanaka and Y. Nakayama: Intermetallics, 3 (1995) 369.

[109] I. Song and N. N. Thadhani: J. Mater. Synth. Proc., 1 (1993) 347.

[110] T. Takeuchi, M. Takahashi, K. Ado, N. Tamari, K. Ichikawa, S. Miyamoto, M. Kawahara, M. Tabuchi and H. Kageyama: J. Amer. Ceram. Soc., 84 (2001) 2521. 